\title{
Performance Tasks as a Mediator to Communicating in English and for Enhancing Language Learner Engagement
}

\author{
Saeko TOYOSHIMA \\ Tsuru University
}

\begin{abstract}
This paper discusses whether technology-based performance tasks could be a mediator to communicating in English and enhance language learner engagement. Through action research, the study investigated how low-proficiency Japanese English-language learners could change their attitude toward communicating in their target language by completing a performance task that involve making and presenting a digital portfolio. The students had to mediate between themselves linguistically and contextually when completing the performance task. The study adapted two types of questions in a questionnaire: one involved a three-point Likert scale and the other had open-ended questions about the performance task. Twenty-five students completed the questionnaire. The students had to answer the questionnaire twice, once at the end of the first semester and once at the end of the second semester. The data from the open-ended questions were analyzed qualitatively from a phenomenological research perspective. The students' comments on the task showed that they positively engaged in the performance task throughout the two semesters by reflecting on themselves as English learners, with some difficulty mediating themselves in L1 and L2.
\end{abstract}

Keywords: Performance task, mediation, language learner engagement, phenomenological research methodology

\section{Introduction}

The present study investigated whether Japanese university students with low English language proficiency could enhance their language learner engagement by mediating themselves linguistically in Japanese and English as well as contextually in a certain learning environment through a performance task. Many Japanese universities have to admit students with low proficiency in English (CEFR A1) because of various admission requirements. Several practices for such low proficiency students in Japanese universities appear to be aimed at imparting linguistic knowledge first rather than improving communicative abilities (e.g., Nakamura, 2005). However, given the present situation in Japanese education, it seems that many Japanese learners lack experience of communicative practices in English classes as well as experience using English outside of the classroom (Toyoshima, 2016), particularly with regard to expressing themselves in English at the CEFR A1 level. It is assumed that many persons at that level would have 
difficulty engaging in communicative tasks in English because of their lack of experience coupled with their anxiety about their proficiency. Thus, this study introduced a performance task as an action research, namely making and presenting a digital portfolio about various topics related to textbook materials, for the students to mediate themselves in order to communicate in English and enhance their engagement in the task. The task was conducted in a university English class for first-year students using the computer assisted language learning (CALL, hereafter) system. The study investigated how the students' language learner engagement was enhanced in completing the task by means of a questionnaire with open-ended questions and by applying the phenomenological research perspective. Finally, pedagogical and research implications are discussed.

\section{Literature Review}

\subsection{Mediation to communicate and engage in language learning}

Most second/foreign language (SL/FL) learners who started learning in formal educational settings have lived in their L1 world while acquiring their L1 and establishing their L1 selves. This means that such learners are already able to engage in self-mediation by activating their L1 when interacting with their peers or by themselves (Antón \& DiCamilla, 1999; DiCamilla \& Antón, 1997). Sociocultural theory, which has been applied for SL/FL pedagogies (e.g., Lantolf, 2000), claims that language, that is, interaction, is significantly connected to thought, that is, cognition. In other words, language is the principal semiotic tool for mediating our thoughts, on both the social and the individual plane. Hence, depriving L2 learners of L1 entails depriving them of two efficient tools for learning: - "the L1 and effective collaboration" (Antón \& DiCamilla, 1999, p. 245). This suggestion follows Vygotsky’s (1986) concept of learning a foreign language: "In learning a new language, one does not return to the immediate world of objects and does not repeat past linguistic developments but uses instead the native language as a mediator between the world of objects and the new language" ( $p$. 161). Grenfell and Harris (1999) claim that such a learning experience is "problematic" and developing a linguistic competence is "much about mediating or control with respect to the world (the language to express and direct it), others (the language to understand and develop relationships), and self (to express what one needs to say about oneself and how to act)" (emphasis added by the present author) (p. 43). In adult L2 learners with low proficiency, the process of "the whole [array of] learning experiences" might be more "problematic" than that of other levels of learners, as they might have low willingness to communicate in their L2 (e.g., Tan \& Phairot, 2004), thus, they need to "mediate" or "control" themselves between the L1 and L2 worlds by activating both languages to learn and communicate in L2.

\subsection{Theoretical features of language learner engagement}

The definition of "engagement" must be very simple: learner's "actions" 
driven by something or someone (Mercer, 2019). Mercer and Dörnyei (2020) explained this action as "active participation and involvement in certain behaviors," including external (observable) and internal (cognitive and emotional) engagement (p. 2, original emphasis). This engagement is distinguished from language learner motivation; that is, "Motivation is about intent, whereas engagement is about action" (Mercer, 2019, p. 645). For example, well-motivated language learners may not necessarily engage in learning a target language or participate in pedagogical tasks positively (Mercer, 2019); even if students seemingly engage in a task positively, not all of them positively engage internally because of low motivation (Mercer \& Dörnyei, 2020). Oga-Baldwin (2019) also claimed that engagement should differ from motivation or "intended effort." That is, engagement means learners' exact actions, which emerge from their emotions or thoughts, even if the intended effort does not always lead to the intended goal; this can be described as "Motivation is will and intention, [and] wanting and wishing, [while] engagement is the moment when word turns to deed" (p. 3).

However, without intent, action will not occur; that is, engagement and motivation would be interrelated, or they would include common factors (Mercer, 2019; Noels et al., 2019). Mercer (2019) defined engagement as action predated by motivation or willingness to engage cognitively and affectively (p. 645). On the other hand, in their motivation process model, Noels, Lou, Lascano, Chaffee, Dincer, Zhang, and Zhang (2019) suggested that engagement was conceptualized as the action component of motivation, explaining that engagement should reflect a learner's motivation to complete a task or acquire language materials. Thus, the antecedent of engagement must be the same as that of motivation: a construct of a learner's self, to apply Ryan and Deci's (2000) self-determination theory (SDT) (Mercer, 2019; Noels et al., 2019). Mercer and Dörnyei (2020) developed this discussion for practitioners, encouraging them to consider the following four aspects to construct and facilitate language learner engagement: (1) regarding the learner's mindset as the learner's internal (intrapersonal) facet, including sense of self or competence; (2) the rapport between teacher and learners to enhance learner autonomy; (3) the conscious raising of classroom dynamism and culture for learners to establish a good relationship (interpersonal facet); and (4) the development of pedagogical tasks for learners' sustainable engagement. In addition, Noels, Lou, Lascano, Chaffee, Dincer, Zhang, and Zhang (2019) claimed that language learner engagement involves interacting with the learner's self, which includes competence, autonomy, and relatedness as psychological need or satisfaction, as well as intrinsic, extrinsic (integrated, identified, introjected, and external), and amotivation as orientation, to use SDT terminology (p. 100). Thus, engagement and motivation should be differentiated but viewed as interacting with each other.

\subsection{Task design conducive to language learner engagement}

Tasks for learning a target language have included authentic or nearly real- 
world aspects that learners encounter, even in pedagogical situations, so that they can engage in the tasks in interesting, positive ways (e.g., Ellis, 2017; Kormos \& Wilby, 2019; Norris, Brown, Hudson, \& Yoshioka, 1998; Nunan, 1989; Richards \& Rodgers, 2014; Svalberg, 2018). For learners, the task's learning content and language materials offered by the teacher are also authentic because the learning itself align with what is "real" for them (Met, 1998). However, task engagement must be similar both inside and outside the classroom (Ellis, 2017; Nunan, 1989; Svalberg, 2018). Practitioners have been facing the challenge of including both authenticity (practice to survive in the real world) and pedagogy for language acquisition (psycholinguistic aspects in SLA the ory) in a task (Nunan, 1989).

With respect to engagement in language use during task performance, it is important to discuss who should design the task (Lambert, 2017). By comparing six studies published in Language Teaching Research, Vol. 2(6), Lambert (2017) wrote in an editorial in the issue that the proportion of a learner's involvement in task design, topic, content, details, and language affects learner engagement in L2 use (Audrey, 2017; Butler, 2017; Kormos \& Préfontaine, 2017; Lambert, Philip, \& Nakamura, 2017; Phung, 2017; Qui \& Lo, 2017). The same implication has been drawn in other research and in the practical context (e.g., Dincer, Yesilyurt, \& Noels, 2019; Oga-Baldwin, 2017; Svalberg, 2018). Nevertheless, for many pedagogical situations, a certain syllabus should be established that agrees with each institution's or course's aims and requirements. However, Ellis, Skehan, Li, Shintani, and Lambert (2020) have stated that teachers should have free choice of resources for certain tasks, considering their students' differing needs, as well as flexibility, motivation, and aptitudes in classroom dynamics (p. 207). These would include student-determined tasks, topics, and content and/or materials (Lambert, 2017). This argument concludes that if teachers trust students' task design, they should supervise their students to establish learners' L2 selves as antecedents of language learner engagement as well as determine how they mediate themselves linguistically and contextually (see 2.1 and 2.2).

\section{Method}

\subsection{The pedagogical hypothesis and the research question}

The previous studies discussed in the last section led to the hypothesis that it is possible that pedagogical tasks for English learning would influence learners' mediation to communicate in English and enhance their engagement in learning it. In particular, Japanese adult learners with low English-language proficiency might have negative impressions of the English language, negative L2 selves, low selfefficacy, and high anxiety, which in turn could lead to a low willingness to communicate (e.g., Liu \& Jackson, 2008; Yasuda \& Nabei, 2018). Thus, the present pedagogical study poses the following research question:

Is it possible for low-proficiency English learners to enhance their engagement in communication in English through a language course if their 
learning experience includes a performance task that involves mediating themselves linguistically and contextually?

In this study conducted as action research, the performance task includes both "performance" (in the narrow sense) and "product" (work) (Tanaka, Mizuhara, Mitsuishi, \& Nishioka, 2005).

\subsection{Students}

The participants in this study were first-year students at a Japanese public university located about $100 \mathrm{~km}$ from central Tokyo. They belonged to the sociology department, where about 150 students were registered in English courses, including general English and an English course with the CALL system. The students were divided into five classes depending on English proficiency, from CEFR A1 to B1. There were 30 students in this study whose English level was CEFR A1; they belonged to their department's lowest English proficiency group.

\subsection{The teaching and research procedure}

The class was conducted in a computer classroom with a CALL system. The textbook Keynote 1 (Cengage, 2017) was adopted, and four units were planned for completion in one semester. The students made presentation slides to introduce themselves to the topics determined by the teacher (the present author), all of which were related to the unit's themes (see Appendix 1), aimed at learning linguistic knowledge and allowing the students to practice four skills through each unit's materials. The teacher offered example slides for the students' reference. The presentation slides were called a digital portfolio because the series of the slides introduced each student's personality and preferences to express him/herself. The students made a presentation based on the portfolio, called a portfolio session, twice in a semester. A portfolio session is like a poster presentation at a conference; that is, half of the students stayed in their seats with a computer and presented their portfolios, and the other half moved around to listen to, ask questions, and give comments on several other students' portfolios. They took turns, so that both halves of the class had the opportunity to present their portfolios. The entire session was recorded with an integrated circuit (IC) recorder for assessment (one recorder was offered to each pair of students). After the session, they assessed each portfolio they listened to as an audience by means of a rubric, on the basis of three aspects (contents (alignment with the topic and how interesting the idea is), visuals (design and appeal), and English (appropriateness), considering the two aspects of performance and product of the performance task. They also self-assessed using the same rubric. The teacher assessed both aspects of the performance task for each student's portfolio and recorded sound. It is reasonable that the task should be semi teacher-generated, as the teacher let students decide the content of the portfolio (Lambert, 2017).

Three international exchange study program students (two from 
Scandinavian countries and one from England) participated in the third session of the second semester, as the students in the class were expected to have more authentic communication with non-Japanese speakers in English to determine whether there had been any changes in their engagement. The international students listened to the students' presentations and provided feedback.

The present study adapted a Japanese-language questionnaire with threepoint Likert scale questions, "Yes", "Partially Yes", and "No", as well as openended questions to clarify the reason for the answer to each Likert type question and investigate the students' psychological state while participating in the task (see Appendix 2). The students were asked to answer the questionnaires once at the end of the first semester and once at the end of the second semester. Twentyfive students agreed to answer the questionnaire in both the first and second semesters. They provided their agreement after being informed that they would not be treated disadvantageously in class.

The students were asked to answer the questions anonymously so that their responses would be frank and honest. However, the number of comments differed for each question because the students decided which questions to answer. Their responses emerged from their own experiences as classroom phenomena in what is called "intentional meanings that presented themselves (manifested, appeared) in human consciousness through lived experiences," namely learning English in a particular context (Vagle, 2018, p. 31). Thus, the study applied phenomenological research perspectives, which claim that the researcher, namely, the teacher, should have a "longstanding awareness about the importance of the research questions," recognize "the need for empathetic understanding and trust-building" with students, and engage in "imaginative and on-going reflection" or "see[ing] the world with [students'] eyes" (Bugler-Kisber, 2018, p. 63). The students' responses revealed the representativeness and authenticity of learners who showed their "intentional meanings" through their "lived experiences" of engaging in a particular task for English learning (Bugler-Kisber, 2018; Hitchcock \& Hughes, 1995; Lincoln \& Guba, 1989; Mishler, 1990; Toyoshima, 2007, 2018, 2020; Vagle, 2018). The anonymity and the clear explanation of the action research established trustworthiness and encouraged "trust building" between the students and the teacher/researcher, so that the students' comments would be authentic and representative of the real situation. Thus, such narrative data that emerged phenomenologically should be discussed in terms of authenticity and representativeness rather than in terms of validity and reliability (Hitchcock \& Hughes, 1995; Lincoln \& Guba, 1989; Mishler, 1990; Toyoshima, 2007, 2018, 2020).

\subsection{Analysis}

The study adopted content analysis to evaluate the narrative data collected from the open-ended questions. The data were entered into an Excel sheet to compare the changes between the first and second set of responses (Toyoshima, 
2007; 2018; 2020).

\section{Results and Discussion}

\subsection{A digital portfolio as a mediator for communication}

Via the open-ended questions, the students revealed positive attitudes toward communicating in English through performance tasks. For the first question, "Do you think that you could express yourself in English by making a digital portfolio?" (Appendix 2), asked in the first semester, all students, except those who gave "No Answer", answered "Yes" or "Partially Yes" (Figure 1).

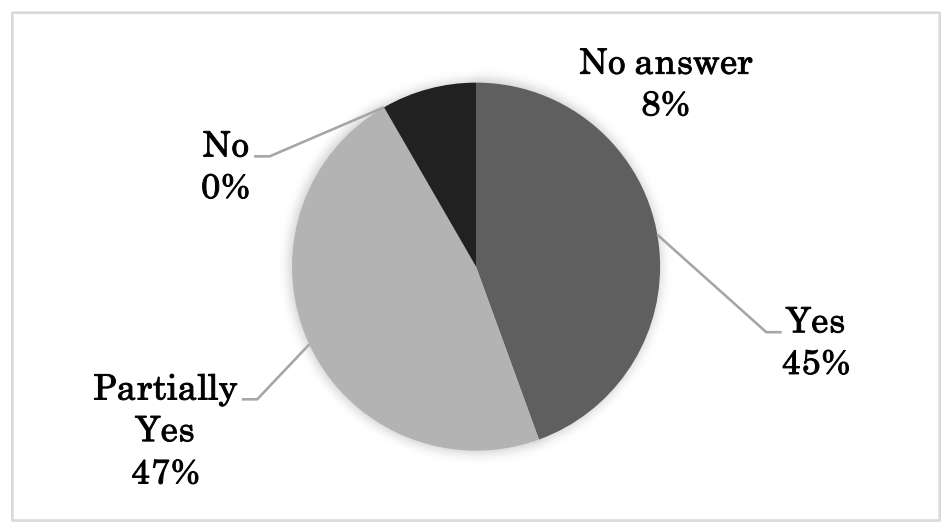

Figure 1. Question 1 "Do you think that you could express yourself in English by making a digital portfolio?" (first semester)

As listed below, some of the comments ${ }^{1}$ on the reason for the answer to the aforementioned question showed that compiling and presenting portfolios caused them to reflect on themselves and understand each other more easily:

C1: Making the portfolio was an opportunity for me to reflect on myself. Listening to others' presentations of their portfolios was an opportunity for me to learn about them. It was fun.

C2: Making my portfolio was difficult for me because I had to find photos or illustrations to accompany the stories, and it was challenging to look up unknown words or structures in dictionaries to write explanations in English, but I enjoyed the sessions because I could express myself.

C1 of the student who answered "Yes," and C2, of the student who answered "Partially Yes", among others, suggest that most of the students found the performance task meaningful in terms of understanding each other through the self-expression facilitated by the portfolios, although compiling the portfolios and presenting them in English constituted the most they could do in the two semesters. In the second semester, the result of the first question was slightly different (Figure 2). 


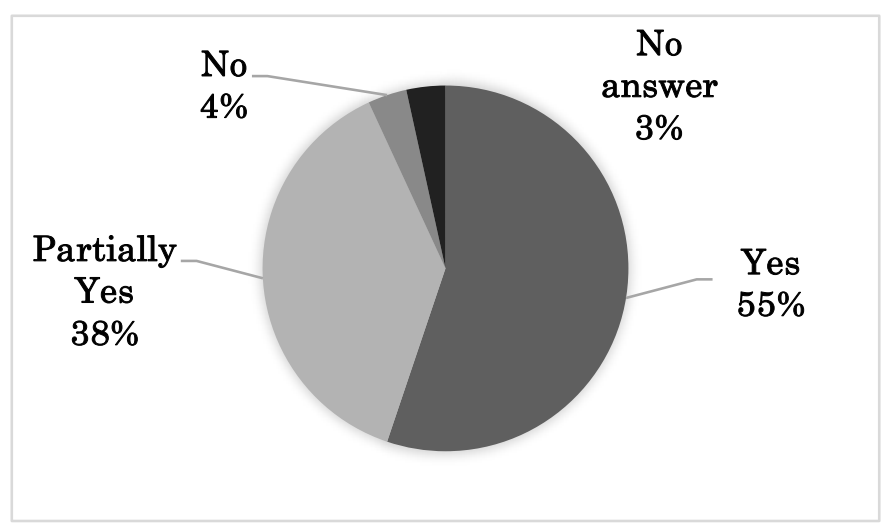

Figure 2. Question 1 "Do you think that you could express yourself in English by making a digital portfolio?" (second semester)

The reasons for the answers are as follows:

C3: The topics were familiar to me, and it was easy to express myself. Everyone listened to me encouragingly.

C4: I didn't have enough English ability enough to express myself.

The students had experienced authentic communication with the international students during the semester. The result showed that the number of students who answered "Yes" increased, which indicates that they had become more confident in expressing themselves in English, as C3 showed. On the other hand, those who answered, "Partially Yes" and "No," might have become aware of their English ability through the authentic communication as revealed in $\mathrm{C} 4$. The change in the answer to the first question between two semesters suggests that more students felt that they could express themselves better through the portfolio.

However, the response to the questions regarding whether the students could make themselves understood in English through presentation with their portfolio was different. For Question 3, "Do you think that you could make yourself understood by the audience when you present your portfolio?" (Appendix 2), asked in the first semester, most students thought that they could make themselves understood in English fully or partially (Figure 3). 


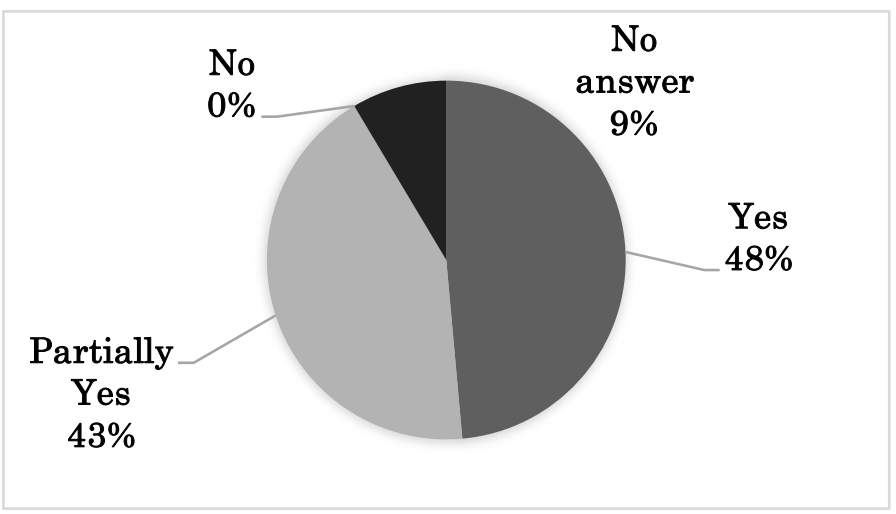

Figure 3. Question 3 "Do you think that you could make yourself understood by the audience when you present your portfolio?" (first semester)

The students' comments on the task were positive overall. The students who answered "Partially Yes" to the aforementioned question at the end of the first semester revealed the following thoughts about the task:

C5: The sessions were good opportunities for me to improve my English. I especially feel I have improved my speaking skill.

C6: It appeared difficult for the audience to understand me if I used unfamiliar expressions, while it became boring if I used only simple expressions. It was difficult to select the best ones.

C5 indicated that the student might have developed a more positive attitudes toward speaking in English than before, whereas C6 indicated that the student was struggling between what he/she wanted to express and how he/she should express in English.

In the second semester, on the other hand, more students answered, "Partially Yes" (Figure 4).

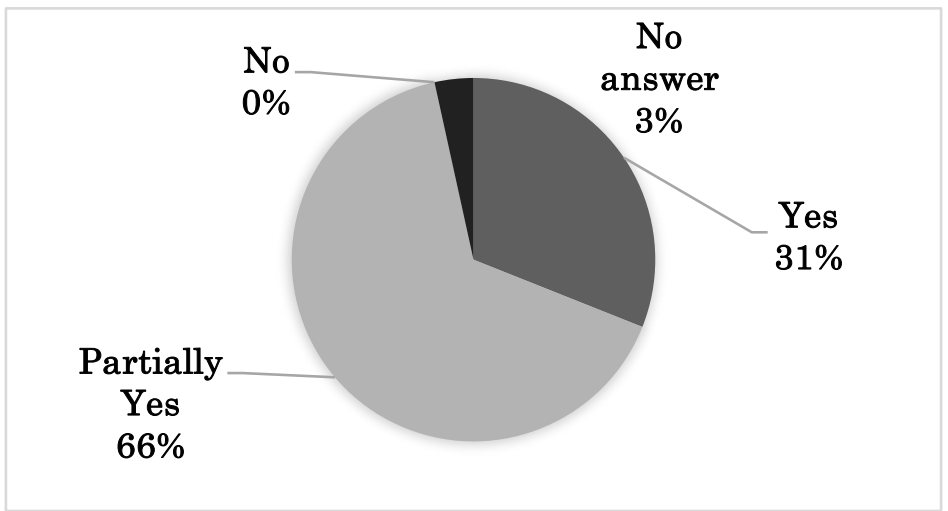

Figure 4. Question 3 "Do you think that you could make yourself understood by audience when you present your portfolio?" (second semester) 
The reason for the answer "Partially Yes" was mostly the lack of inadequate English-speaking skills, according to the comments on the communicative task. That might be because they might have struggled with responding to questions asked by the international students in the third session or with expressing more than what they were capable of in the second semester. However, some of them attempted to make themselves understood in English through their portfolio and their limited English ability:

C7: I couldn't say what I wanted to express in the sessions because I was anxious about my limited English vocabulary and grammatical knowledge, but I could make my portfolio using words and expressions I already knew.

C8: I considered how to make the audience understand my portfolio by adding appropriate illustrations or a suitable letter font.

C9: I don't think my portfolios were good but I'm sure now that I could make myself understood by the audience.

Comments C7, C8, and C9 suggest that the students had been struggling with the gap between their L1 (Japanese) and L2 (English) worlds; that is, they attempted to apply L1 experiences to L2 (Grenfell \& Harris, 1990), which would make them aware of themselves more objectively than in the first semester. $\mathrm{C} 7$ reveals one student's anxiety about communicating in English. Such struggles during mediation should be the gateway to acquisition; that is, a "sprout" of becoming an L2 user with multicompetence in L1, interlanguage, and L2 (Cook, 2008). They must go through the process of acquiring English for the first time if they do not have experience with second-level education. On the other hand, C8 and C9 reveal one student's experience with personal achievement in the process of mediation while making and presenting the portfolio.

The answers to Question 4, "Do you think that you could understand your classmates through their portfolio and presentation?" (Appendix 2), were not largely changed between the two semesters, although more students felt that they could understand their classmates through their presentation and portfolios (Figure 5 and Figure 6).

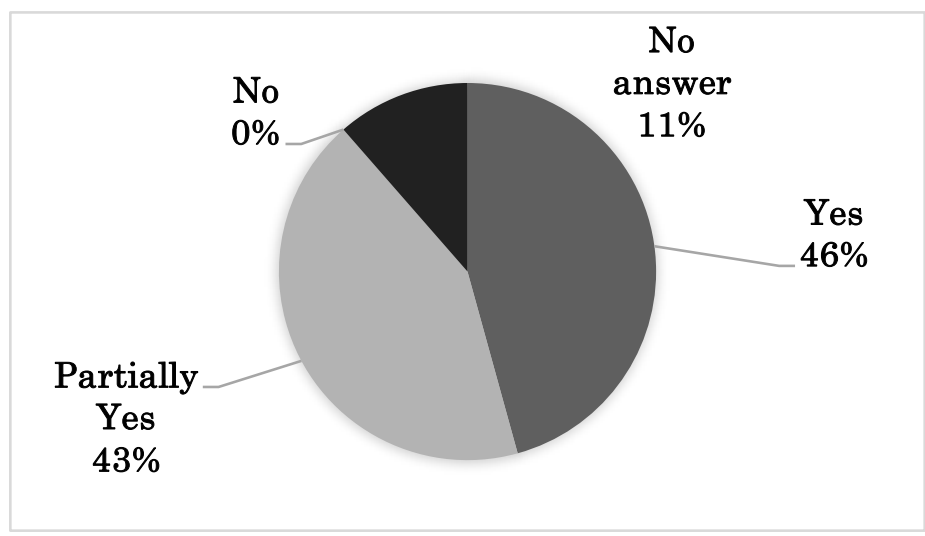


Figure 5. Question 4 "Do you think that you could understand your classmates through their portfolio and presentation?" (first semester)

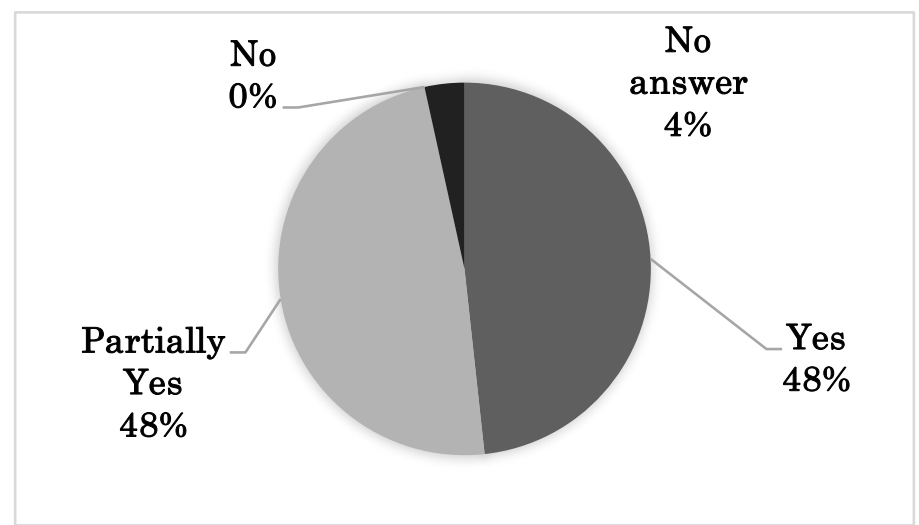

Figure 6. Question 5 "Do you think that you could understand your classmates through their portfolio and presentation?" (second semester)

However, communication with international students in English in the third session might influence students' attitude toward learning English, even though some of them had experienced struggles as discussed above. At the end of the second semester, the students' comments on the portfolio session included their experiences of authentic communication with the international students in English and demonstrated their recognition of the differences among students:

C10: The session with the international students was a precious experience for me. They gave me good advice about my presentation, so I want to use English more confidently from now on.

C11: The students' ideas and comments were interesting, and I found them different from each other. I think I learned a lot about them.

C10 suggests that students' feelings of anxiety toward and incompetence in English would make them avoid communicating in English (e.g., Liu \& Jackson, 2008). Once students feel confident about communicating in English because of positive experiences in which they had made themselves understood in real-life situations, they are likely to be willing to communicate in English, even with low proficiency. C11, on the other hand, suggests that the students realized the differences among students, including among the international students, by expressing themselves via the digital portfolios in the second semester. This experience might influence their attitude to intercultural friendship; in other words, they might realize that the reason for learning English is to facilitate communication with others, including with non-Japanese speakers, to get to know each other well. This indicates that the task could contribute to "conscious raising of classroom dynamism and culture for learners to establish a good relationship 
(interpersonal facet)", which would enhance language learner engagement discussed in the next section (Mercer and Dörnyei, 2020; see 2.2 above).

The positive feeling of achievement or enjoyment while communicating in English could be defined as a different dimension from learning English in an anxious state, as Dewaele and MacIntyre (2016) discussed. The present study claims that the performance task promotes mediation between task, language, and context engagement by encouraging students to self-reflect and communicate with others in English. It also claims that the students gradually realize the meaningfulness of the engagement, as the task satisfies Svalberg (2018)'s model of meaningfulness (see 3.3), revealing a positive attitude toward communicating in English through it; on the other hand, mediation between L1 and L2 would be "problematic" and may continue to cause students to struggle (Grenfell \& Harris, 1990).

\subsection{Establishing L2 learner self to enhance language learner engagement in the classroom}

Self-reflection and interaction with other students through the task might encourage students to recognize themselves as English learners. The comments about the task showed slight changes in students' self-awareness as English learners:

C12: The task was a good opportunity to think about myself and others.

C13: I think I could express myself very well by reflecting on and learning about myself through this activity. Besides, it was a good experience to write about many topics.

C12 and C13, stated in the first semester, indicate that the performance task made the students self-reflect and was a good way to encourage them to make friends with each other, as they saw each other only once a week in this class. In other words, it is possible that students would start the process of establishing their self as L2 learners by engaging in social interactions through the task; these interactions became intersubjective activities with others (Toyoshima, 2007). This "interpersonal facet" between the student's self and others would be a significant factor in enhancing language learner engagement, as discussed in the last section (Mercer and Dörnyei, 2020; see 2.2 \& 4.1). In addition, C14 could be interpreted as expressing the student's sense of fulfillment or accomplishment with regard to engagement in the task after finishing the two sessions in the first semester.

C14: I consider the experiences from the two sessions to be my good fortune. The activity attracted me very much in terms of the fact that many Japanese people would be poor at expressing themselves.

The student might be one of the "many Japanese people", who have metacognitive 
awareness of him/herself and realize that the task would enable him/herself to overcome his/her problem. This suggests that the student would establish "learners' mindset as the learner's internal (intrapersonal) facet, including sense of self or competence" (Mercer and Dörnyei, 2020; see 2.2).

In the second semester, some students saw improvements in their fluency of communication as well as in their engagement in the classroom as a result of their experiences in the four sessions:

C15: It was sometimes hard but overall fun to make the portfolio. Besides, I felt myself being able to use English expressions faster than before.

C16: I could check my English expressions objectively by writing on the portfolio slides, and I think that I could learn English more by taking part in the task than just listening to the teacher's lectures.

C17: This class introduced "active learning" and helped me learn a lot because I could express myself clearly and learn about my classmates in English.

C18: I could learn English enjoyably because it was very interesting to make and present my portfolio and listen to the others' present theirs.

C15 implies that the task might make students realize their own improvements in L2 proficiency, which would be a key factor in establishing a sense of self and integrating the meaningfulness of learning English into the learners' selves (Ryan \& Deci, 2000; Toyoshima, 2016); this would in turn be conducive to language learner engagement and intrinsic motivation (Mercer, 2019; Mercer \& Dörnyei, 2020). C16, C17, and C18 suggest that students realized what they should aim for as English learners; that is, they should learn English by taking on the role of agent and legitimate participant, rather than merely being recipients of knowledge during class; that is, being members of a passive or "empty" audience, even with low proficiency (Dewaele \& MacIntyre, 2016; Firth \& Wagner, 1997, 1998; Sfard, 1998). C16 and C17 also indicate that this performance task, as in John Dewey's (1938) "learning by doing," which forms part of task-based language teaching principles (Ellis et al., 2020), would be preferred and suitable for learning engagement in the classroom and might yield an effective learning outcome. C1 8 shows that students could enjoy learning English by engaging in a task, which might energize language learner engagement (Dörnyei \& Muir, 2019; Ibrahim, 2016; Mercer, 2019). The comments imply that the task would encourage the students to adjust their mindsets toward learning English: they might realize that the goal of learning English should be to achieve "something challenging and [develop] one's competences," rather than to get "good grades and [look] competent" (Mercer, 2019, p. 651). This might be because their performance was not evaluated for English accuracy but for conveying meaning appropriately. In addition, the entire process of the performance task requires the students to selfmediate through aspects such as competence, autonomy, and relatedness with 
others, which would enhance language learner engagement and facilitate integration of L2 into learner's self in the SDT's motivational model (Noels et al., 2019; Ryan \& Deci, 2000; see 2.2). The study suggests that the students become self-aware as being English learners by engaging in the task, which would probably lead to their willingness to communicate in English.

\subsection{Issues on task design: who should design tasks?}

The task was teacher-generated; the students were not allowed to select the task or choose the topics. The following comment reveals dissatisfaction with the topics the teacher offered (see Appendix 2):

C19: I could not relate personally to the topic "Someone with a great talent," and I could not find an appropriate subject for the topic. I prefer topics of my own choosing, like "How about this dream job?"

C19 expresses one student's desire to be an agentic learner and his/her hope for the opportunity to select a topic. The comment suggests that topic unfamiliarity or authorized topic selection might affect students' engagement (Dincer et al., 2019; Oga-Baldwin, 2017; Qui \& Lo, 2017). Moreover, the following comments criticized the teacher's instruction and development of the task:

C20: I didn't have enough time to make my portfolio. The teacher should have introduced each topic earlier.

C21: I think the teacher should have explained the production of the portfolio in greater detail.

C20 and C21 reveal students' dissatisfaction with the teacher's instruction, although the teacher, presented the topics in the course syllabus in advance and explained each topic in detail with examples. These feelings affect the establishment of the "rapport between teacher and learners to enhance learner autonomy" which is one of the aspects in constructing and facilitating language learner engagement (Mercer and Dörnyei, 2020; see 2.2). The comments of the students engendered the question of a balance between learner- and teachergenerated task design to consider another aspect of enhancing language learner engagement; that is, "the development of pedagogical tasks for learners" sustainable engagement" (Lambert, 2017; Mercer and Dörnyei, 2020; see 2.2 and 2.3).

\section{Practical implication and further research}

The present research yielded several findings for the author as the students' English teacher. First, in the English class, most of the students behaved as agents and legitimate participants by mediating themselves in the learning context, the performance task, and with regard to the learning materials, despite their low 
English-language proficiency; however, some revealed difficulty in mediating themselves in Japanese and English. This indicates that the performance task of making and presenting a digital portfolio could enhance language learner engagement in communicating in English (Svalberg, 2018), although mediation between L1 and L2 might still be problematic and challenging for some students (Grenfell \& Harris, 1999). It is therefore suggested that the teacher should demonstrate flexibility by letting the students create task content or topics to encourage them to enhance their language learner engagement both inside and outside the classroom; that is, practitioners should create a balance between learner- and teacher-generated content in task design, regardless of the educational situations or restrictions (see 2.3). Further, support should be provided throughout the process in terms of linguistic aspects and task compression.

Regarding the implications for further research on language learner engagement, practitioners as researchers should study the classroom in an ecological learning context and investigate participants in the situated learning place more deeply (Mercer, 2019). It is possible that different cases would yield different results and findings, even if the same task is adopted. The present study was exactly ecologically situated in an English classroom using a CALL system that was introduced for Japanese English-language learners with low proficiency at a local university in Japan, which would turn out to be one case of the "ecologies of engagement" that emerged from and certainly go back to the antecedents of learner engagement (Mercer, 2019, p. 657, also see 2.2). The more ecological and situated the research context for observing language learner engagement, the more individual and subjective the outcome under a particular research condition (Svalberg, 2018). The present study investigated students' responses to openended questions to reveal the variety among students and show different reactions to the performance task. The study indicates that the phenomenological research method is suitable for investigating sensitive emotions in L2 language learners (Ibrahim, 2016; Piniel \& Albert, 2019); it should therefore be suitable for investigating L2 learners' psychological state while learning a target language.

\section{Note}

${ }^{1}$ All comments were written in Japanese and the author translated them into English.

\section{Acknowledgements}

I thank my students for cooperating with the research. I also thank Tsuru University for providing financial support to conduct the research.

\section{References}

Akbari, E., Naderi, A., Simons, R-J., \& Pilot, A. (2016). Student engagement and foreign language learning through online social networks. Asian-Pacific Journal of Second and Foreign Language Education, 1, 1, 1-22. 
Antón, M. \& DiCamilla, F. J. (1999). Socio-cognitive functions of L1 collaborative interaction in the L2 classroom. The Modern Language Journal, 83, 2, 233 247.

Aubrey, S. (2017). Inter-cultural contact and flow in a task-based Japanese EFL classroom. Language Teaching Research, 21, 6, 717-734.

Butler, Y. G. (2017). Motivational elements of digital instructional games; a study of young L2 learners' game designs. Language Teaching Research, 21, 6, 735-750.

Buter-Kisber, L. (2018). Qualitative inquiry: thematic, narrative and arts-based perspectives (2nd ed). Sage.

Cook, V. (2008). Second language learning and language teaching. London, UK: Hodder Education.

Dewaele, J-M. \& MacIntyre, P. D. (2016). Foreign language enjoyment and foreign language classroom anxiety: the right and left feet of the language learner. In P. D. MacIntyre, T. Gregersen, \& S. Mercer (Eds.), Positive psychology in SLA (pp.215-236). Multilingual Matters.

Dewey, J. (1938). Experience and education. New York, NY: MacMillan.

DiCamilla, F. J. \& Antón, M. (1997). Repetition in the collaborative discourse of L2 learners: a Vygotskian perspective. The Canadian Modern Language Review, 53, 4, 609-633.

Dincer, A., Yesilyurt, S., \& Noels, K. A. (2019). Self-determined engagement in language learning: The relations among autonomy-support, psychological needs, and engagement. Cumhuriyet International Journal of Education, 8, 4, $1130-1147$.

Dörnyei, Z. (2002). The motivational basis of language learning tasks. In P. Robinson (Ed.), Individual differences and instructed language learning (pp.137-158). John Benjamin Publishing.

Dörnyei, Z. \& Muir, C. (2019). Creating a motivating classroom environment. In X. Gao (Ed.), Second handbook of English language teaching (pp. 719-735). Springer International Publishing.

Ellis, R. (2017). Position paper: moving task-based language teaching forward. Language Teaching, 50, 4, 507-526.

Ellis, R., Skehan, P., Li, S., Shintani, N., \& Lambert, C. (2020). Task-based language teaching; theory and practice. Cambridge University Press.

Firth, A. \& Wager, J. (1997). On discourse, communication, and (some) fundamental concepts in SLA research. The Modern Language Journal, 81, iii, 285-300.

Firth, A. \& Wager, J. (1998). SLA property: no trespassing! The Modern Language Journal, 82, i, 91-94.

Gardener, R. C. \& Lambert, W. E. (1972). Attitudes and motivation in second language learning. Newbury House.

Grenfell, M. \& Harris, V. (1999). Modern languages and learning strategies. London, UK: Routledge. 
Henry, A. (2019). Directed motivational currents: extending the theory of L2 vision. In M. Lamb, K. Csizér, A. Henry, \& S. Ryan (eds), The palgrave handbook of motivation for language learning (pp.139-161). Palgrave Macmillan.

Hitchcock, G., \& Hughes, D. (1995). Research and the teacher: A qualitative introduction to school-based research. London, UK: Psychology Press.

Ibrahim, Z. (2016). Affect in directed motivational currents; positive emotionality in long-term L2 engagement. In P. D. MacIntyre, T. Gregersen, \& S. Mercer (Eds.), Positive psychology in SLA (pp.258-281). Multilingual Matters.

Kormos, J. \& Préfontaine, Y. (2017). Affective factors influencing fluent performance: French learners' appraisals of second language speech tasks. Language Teaching Research, 21, 6, 699-716.

Kormos, J. \& Wilby, J. (2019). Task motivation. In M. Lamb, K. Csizér, A. Henry, \& S. Ryan (Eds), The palgrave handbook of motivation for language learning (pp.267-286). Palgrave Macmillan.

Lamb, M., Csizér, K., Henry, A., \& Ryan, S. (Eds), The palgrave handbook of motivation for language learning. Palgrave Macmillan.

Lambert, C. (2017). Tasks, affect and second language performance. Language Teaching Research, 21, 6, 657-664.

Lambert, C., Philip, J., \& Nakamura, S. (2017). Learner-generated content and engagement in second language task performance. Language Teaching Research, 21, 6, 665-680.

Lantolf, J. P. (Ed.) (2000). Sociocultural theory and second language learning. Oxford University Press.

Lincoln, Y. S., and Guba, E. G. (1985). Naturalistic inquiry (Vol. 75). Sage.

Liu, M. \& Jackson, J. (2008). An exploration of Chinese EFL learners' unwillingness to communicate and foreign language anxiety. The Modern Language Journal, 92, i, 71-86.

Lou, N. \& Noels, K. A. (2019). Language mindsets, meaning-making, and motivation. In M. Lamb, K. Csizér, A. Henry, \& S. Ryan (Eds), The palgrave handbook of motivation for language learning (pp.537-559). Palgrave Macmillan.

Mercer, S. (2019). Language learner engagement: setting the scene. In X. Gao (Ed.), Second handbook of English language teaching (pp. 643-660). Springer International Publishing.

Mercer, S. \& Dörnyei, Z. (2020). Engaging language learners in contemporary classrooms. Cambridge University Press.

Met, M. (1998). Curriculum decision-making in content-based language teaching. In J. Cenoz \& F. Genesee (Eds.), Beyond bilingualism (pp. 35-63). Multilingual Matters.

Mishler, E. G. (1990). Validation in inquiry-guided research: the role of exemplars in narrative studies. Harvard Educational Review, 60, 4, 415-442.

Nakamura, T. (2005). Daigaku niokeru rimediaru kyoiku eno teigen: Eigo no 
tsumazuki ni kanshite [Suggestion to remedial education at university relevant to learners who have problem in learning English]. Tokyo: Daigakukyoiku Shuppan.

Noels, K. A., Lou, N. M., Lascano, D. I., Chaffee, K. E., Dincer, A., Zhang, Y. S. D., \& Zhang, X. (2019). Self-determination and motivated engagement in language learning. In M. Lamb, K. Csizér, A. Henry, \& S. Ryan (Eds), The palgrave handbook of motivation for language learning (pp.95-115). Palgrave Macmillan.

Norris, J. M., Browns, J. D., Hudson, T., \& Yoshioka, J. (1998). Designing second language performance assessments. Second Language Teaching \& Curriculum Center, University of Hawai'i.

Nunan, D. (1989). Designing tasks for the communicative classroom. Cambridge University Press.

Oga-Baldwin, W. (2019). Acting, thinking, feeling, making, collaborating: the engagement process in foreign language learning. System, 86, November, 102128.

Qiu, X. Lo, Y. Y. (2017). Content familiarity, task repletion and Chinese EFL learners' engagement in second language use. Language Teaching Research, 21, 6, 681-698.

Phung, L. (2017). Task preference, affective response, and engagement in L2 use in a US university context. Language Teaching Research, 21, 6, 751-766.

Piniel, K. \& Albert, A. (2019). Motivation and flow. In M. Lamb, K. Csizér, A. Henry, \& S. Ryan (Eds), The palgrave handbook of motivation for language learning (pp.579-597). Palgrave Macmillan.

Richards, J. C. \& Rodgers, T. S. (2014). Approaches and methods in language teaching (3rd ed). Cambridge University Press.

Ryan, R. M. \& Deci, E. L. (2000). Self-determination theory and the facilitation of intrinsic motivation, social development, and well-being. American Psychologist, 55, 1, 68-78.

Sfard, A. (1998). On two metaphors for learning and the dangers of choosing just one. Educational Researcher, 27, 2, 4-13.

Svalberg, A. (2009). Engagement with language: Interrogating a construct. Language Awareness, 18, 3-4, 242-258.

Svalberg, A. (2018). Researching language engagement; current trends and future directions. Language Awareness, 27, 1-2, 21-39.

Tan, K. E., \& Phairot, E. (2018). Willingness to Communicate among Thai EFL Students: Does English Proficiency Matter?. Journal of Asia TEFL, 15(3), 590-602.

Tanaka, K., Mizuhara, K., Mitsuishi, H., \& Nishioka, K. (2011). Atarashii jidai no kyoikukatei [Curriculum in the new era] 3rd ed. Tokyo: Yuhikaku Alma.

Tran, P. (2018). Enhancing online language learning task engagement through social interaction. Australian Journal of Applied Linguistics, 1, 2. 88-101.

Toyoshima, S. (2007). Evidence from learning histories elicited through structured 
conversations: continuity in English language learning in Japan. Unpublished doctor's thesis. Department of Educational Studies, The University of York, England.

Toyoshima, S. (2016). Factors Influencing Motivation Formation for Learning English in Japan. Akita International University Global Review, Vol.7, pp.23-46.

Toyoshima, S. (2018). Meritokurashi niyoru nihonjineigogakushusha no katto: eigogakushudoki keiseikatei ni oyobosu eikyo [Struggles of Japanese learners of English against meritocracy: The Influences on the Process of Forming Motivation]. The Tsuru University Review, 88, 99-115.

Toyoshima, S. (2020). Influence of assessment styles in English classes on Japanese English learners' beliefs and attitudes. The Tsuru University Review, 91, 109-130.

Vagle, M. D. (2018). Crafting phenomenological research. New York, NY: Routledge.

Vygotsky, L. S. (1986). Thought and language. Cambridge, MA: The MIT Press.

Yashima, T. (2002). Willingness to communicate in a second language: the Japanese EFL context. The Modern Language Journal, 86, 1, 54-66.

Yasuda, T. \& Nabei, L. (2018). Effects of coping strategies on language anxiety of Japanese EFL learners: investigating willingness to communicate. Language Teaching and Research, 9, 5, 905-915.

\section{Appendices \\ Appendix 1: Topics of the "digital portfolio"}

First semester

1. Listen to My Favorite Music / Let's Watch My Favorite Movie

2. This is My "Must" Thing

3. How about this "Dream" Job?

4. Someone with Great Abilities

Second semester

5. Can I Introduce My Best Friend?

6. The Wildest Place in My Hometown

7. "I did it!": My Achievement in My Life

8. I Want ... near the Campus! (each student filled something in the blank)

Appendix 2: Three-point Likert scale and open-ended questions (Japanese translated into English by the present author)

1. Do you think that you could express yourself in English by making digital portfolio? - "Yes" / "Partially Yes" / "No

2. Please write the reason for the answer to Question 1.

3. Do you think that you could make yourself understood by the audience when you present your portfolio? - "Yes" / "Partially Yes" / "No

4. Do you think that you could understand your classmates through their 
portfolio and presentation? - "Yes" / "Partially Yes" / "No

5. Please feel free to write your comments on making and presenting digital portfolio. 